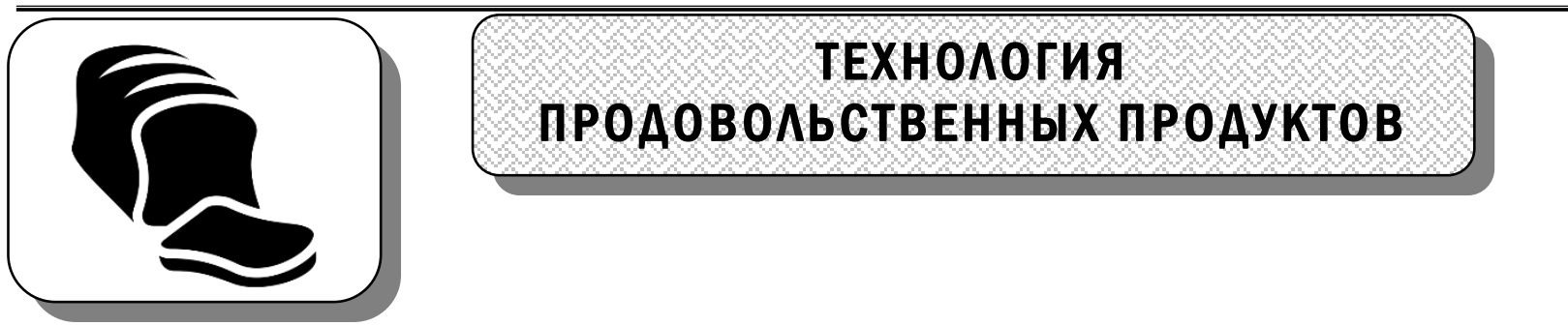

УДК 633.16: 631.52

DOI: $10.36718 / 1819-4036-2019-12-125-130$

А.В. Сумина, В.И. Полонский, Т.М. Шалдаева, М.Т. Шулбаева

\title{
СОДЕРЖАНИЕ АНТИОКСИДАНТОВ В ПРОДУКТАХ ХАКАССКОЙ НАЦИОНАЛЬНОЙ КУХНИ НА ОСНОВЕ ЗЕРНА ЯЧМЕНЯ
}

\author{
A.V. Sumina, V.I. Polonsky, \\ T.M. Shaldaeva, M.T. Shulbaeva
}

\section{THE CONTENT OF ANTIOXIDANTS IN THE PRODUCTS OF THE KHAKAS NATIONAL CUISINE BASED ON BARLEY GRAIN}

Сумина А.B. - канд. С.-х. наук, доц. каф. химии и геоэкологии Хакасского государственного университета им. Н.Ф. Катанова, г. Абакан.

E-mail: alenasumina@list.ru

Полонский В.И. - д-р биол. наук, проф. каф. ландшафтной архитектуры и ботаники Красноярского государственного аграрного университета, г. Красноярск.

E-mail: vadim.polonskiy@mail.ru

Шалдаева T.M. - канд. биол. наук, науч. сотр. Центрального сибирского ботанического сада СО РАН, г. Новосибирск.

E-mail: tshaldaeva@yandex.ru

Шулбаева М.T. - канд. техн. наук, доц. каф. технологического проектирования пищевых производств Кемеровского государственного университета, г. Кемерово.

E-mail: sh-m-t@yandex.ru

Цель работы - изучение суммарного содержания антиоксидантов (ССА) в национальном хакасском продукте талган, полученном из ячменного зерна. Талган изготавливали по традиционному (обжаривание, измельчение) и инновационному (измельчение, обжаривание) способам. В данной серии опытов использовали три сорта ячменя: Биом и Красноярский 91 (nо типу зерновки относятся к пленчатым), Омский голозерный 1 (к голозерным формам). Bce образцы выращивались на территории
Sumina A.V. - Cand. Agr. Sci., Assoc. Prof., Chair of Chemistry and Geoecology, N.F. Katanov Khakass State University, Abakan.

E-mail: alenasumina@list.ru

Polonsky V.I. - Dr. Biol. Sci., Prof., Chair of Landscape Architecture, Botany, Agroecology, Krasnoyarsk State Agrarian University, Krasnoyarsk.

E-mail: vadim .polonskiy@mail.ru

Shaldaeva T.M. - Cand. Biol. Sci., Staff Scientist, Central Siberian Botanical Garden SB RAS, Novosibirsk.

E-mail: tshaldaeva@yandex.ru

Shulbaeva M.T. - Cand. Techn. Sci., Assoc. Prof., Chair of Technological Design of Food Productions, Kemerovo State University, Kemerovo.

E-mail: sh-m-t@yandex.ru

Бейского госсортоучастка Республики Хакасия, которая характеризуется благоприятными климатическими условиями с позиций выращивания зерна с повышенным содержанием антиоксидантов. Для определения ССА в зерне использовали 2 растворителя - бидистиллированную воду и 70\%-й этанол. Измерение ССА выполняли на приборе «Цвет Яуза01-АА». В качестве образца сравнения использовали галловую кислоту. У всех образцов талгана, изготовленного по традиционному 
способу, наблюдалось снижение ССА относительно цельного зерна. Среди трех образцов более высокие значения ССА обнаружены в ячменном талгане, полученном из сорта Омский голозерный 1, далее располагаются пленчатые сорта - Биом и Красноярский 91. При использовании инновационного способа приготовления талгана из зерна сортов Биом и Омский голозерный 1 наблюдалось увеличение уровня ССА в талгане по сравнению с цельным зерном. В случае изготовления талгана из образиа Красноярский 91 было выявлено снижение величины ССА, но не такое заметное, как при традиционном способе. Суммарное содержание антиоксидантов в ячменном талгане существенно зависело от способа изготовления, с помощью трехфакторного анализа установлено, что на долю данного показателя приходится более $80 \%$.

Ключевые слова: талган, ячмень, сорт, зерно, бидистиллированная вода, спирт, суммарное содержание антиоксидантов, элюент.

The aim of the work was to study the total antioxidants content (TAC) in national Khakass product Talgan, obtained from barley grain. Talgan was made by traditional (frying, grinding) and innovative (grinding, frying) methods. Three varieties of barley were used in this series of experiments: Biom and Krasnoyarsky 91, (according to the type of caryopsis, belonging to husked type), and Omsk Goloserny 1, (to hull-less forms). All the samples were grown on the territory of Beysk state section of the Republic of Khakassia, characterized by favorable climatic conditions from the point of view of growing grain with a high content of antioxidants. For the determination of TAC in grain, 2 solvents were used: double- distilled water and $70 \%$ ethanol. TAC measurement was performed on Yauza01-AA Color instrument. Gallic acid was used as a reference sample. All the samples of Talgan made according to traditional method showed the decrease in TAC with the respect to whole grain. Among the three samples higher values of the total antioxidant content were found in barley Talgan made of Omsk Golozerny 1, followed by husked varieties - Biom and Krasnoyarsky 91. TAC increasing in Talgan was observed in comparison with whole grain when using traditional method in the samples made on the basis of Biom and Omsk Golozerny 1. In the case of making Talgan using the sample Krasnoyarsky 91 there was TAC decreasing, but it had lower values than when using traditional method. The total content of antioxidants in barley Talgan significantly depended on manufacturing method, using three-factor analysis it was found out that this indicator accounted more than $80 \%$.

Keywords: Talgan, barley, variety, grain, double-distilled water, alcohol, total content of antioxidants, eluent.

Введение. Согласно данным ВО3, среди всех фракторов, формирующих здоровье населения, до 50 \% приходится на «здоровый образ жизни» (ЗОЖ). Поэтому одно из направлений социальной политики Российской Федерации заключается в создании благоприятных условий и мер по формированию у граждан потребности к 30Ж [1].

Одной из составляющих проблемы является отсутствие у большей части населения страны сбалансированного и функционального питания. На сегодняшний день основным принципам здорового питания в России следует от 40 до $60 \%$ населения [2]. Вместе с тем большую значимость в плане ухудшения здоровья населения приобретают хронические неинфекционные заболевания (болезни системы кровообращения, пищеварения, а также новообразования): у 9,3 \% мужчин и 16,0 \% женщин в возрасте от 14 лет и старше регистрируются заболевания, связанные с питанием [2]. Исследования, выполненные в последнее время в разных странах, подтверждают, что одной из основных причин патологических изменений в человеческом организме, приводящих к развитию неинфекционных болезней, является избыточное содержание в биологических жидкостях свободных кислородных радикалов. Известная свободнорадикальная теория старения и возникновения хронических заболеваний говорит, что на протяжении всей жизни происходит накопление повреждений, вызванных свободными радикалами. Все это приводит к повышенному риску появления неинфекционных болезней [3]. Однако именно эта группа заболеваний может быть предупреждена практически на всех этапах жизни человека через изменение образа его жизни.

Важную роль в укреплении здоровья населения может сыграть включение фуннциональных 
компонентов, таких как антиоксиданты (АО), в ежедневную диету. Кроме того, включение АО в готовую продукцию обеспечивает предупреждение ее порчи и увеличение сроков годности [4]. В развитых странах объем производства данной группы продовольственных товаров достигает 30 \% всего выпуска хлебобулочной продукции при постоянной тенденции к его росту [1]. В России объемы производства специализированных и функциональных хлебобулочных изделий составляют немногим более 100 тыс. тонн в год, при потребности 600-700 тыс. тонн [2].

Научно обосновано, что продукты на основе зерна ячменя имеют высокую питательную ценность и характеризуются наличием разнообразных химических веществ, проявляющих антиоксидантные свойства. Следует отметить, что, хотя продукты на основе зерновых культур считаются одними из основных компонентов питания человека, исследований в области определения их антиоксидантной активности проведено недостаточно [5].

Вместе с тем антиоксиданты поступают в организм человека с пищей практически в течение всей жизни, поэтому особенно важно избежать негативного влияния их избыточных количеств. С другой стороны, самостоятельно человеческий организм не способен синтезировать AO, а их недостаточные концентрации в сырье не обеспечивают сохранения его высокого качества. Эти факты свидетельствуют о необходимости изучения содержания АО в различных видах пищевых продуктов [4].

Цель исследования. Анализ суммарного содержания антиоксидантов в национальном хакасском продукте талган на основе зерна ячменя, полученном традиционным и инновационным способами.

Объект и методы исследования. Объектом изучения служили образцы талгана, изготовленного из измельченного и термически обработанного (обжаренного) зерна ячменя. В работе проводили сравнительное изучение образцов талгана, изготовленного из трех сортов ячменя (табл.1). Все они были выращены на территории Бейского госсортоучастка Республики Хакасия, расположенной в зоне степи предгорий на обыкновенных и южных черноземах. Данная территория характеризуется благоприятными условиями с позиции выращивания зерна с по- вышенным содержанием антиоксидантов [6]. Сорта Биом и Красноярский 91 имеют пленчатую зерновку, Омский голозерный 1 - лишен пленок.

Талган на основе ячменя изготавливали двумя способами. Первый - традиционный (прототипом является изготовление хакасского национального блюда), где на первом этапе производили термическую обработку зерна с последующим его измельчением. Предварительно зерно ячменя с оболочкой (если пленчатая форма) подвергали очистке от посторонних примесей, затем зерно термически обрабатывали (обжаривали) на протяжении 10 минут при $150{ }^{\circ} \mathrm{C}$; далее охлаждали и измельчали до размера частиц 0,25-0,7 мм. К достоинствам данного варианта можно отнести относительную простоту изготовления продукта, к недостаткам - длительную термообработку при высокой температуре, приводящую к частичному разрушению биологически активных веществ, микрои макронутриентов зерна. Поэтому в нашей работе мы использовали и другой вариант изготовления ячменного талгана, разработанный Д.М. Бородулиным и др., при котором менялся порядок действий. Сначала зерно измельчали, а затем обжаривали [7].

Определение суммарного содержания антиоксидантов (ССА) в исходном зерне и пробах ячменного талгана проводили в следующей последовательности: на первом этапе получали водный или водно-спиртовой экстракт, далее фильтровали, а затем с помощью прибора «Цвет Яуза-01-АА» измеряли величину ССА по методу [6].

Статистическая обработка результатов была выполнена с помощью программы обработки данных полевого опыта FieldExpert vl.3 Pro [8] и MicrosoftExcel 2003.

Результаты и их обсуждение. Исходное зерно ячменя имело достоверные межсортовые различия в значении ССА: максимальными уровнями при этом характеризовалось зерно сорта Красноярский 91, минимальными - образца Биом (табл. 2). Исследование уровня ССА в талгане, изготовленном по традиционному и инновационному способу, показало, что существенные различия между сортами в большинстве своем сохраняются. 


\section{Характеристика сортов ячменя, используемых при изготовлении талгана}

\begin{tabular}{|l|c|c|c|}
\hline \multirow{2}{*}{ Показатель } & \multicolumn{3}{|c|}{ Сорт, разновидность } \\
\cline { 2 - 4 } & $\begin{array}{c}\text { Биом, } \\
\text { Нутанс (nutans) }\end{array}$ & $\begin{array}{c}\text { Красноярский 91, } \\
\text { Паллидум (Pallidum) }\end{array}$ & $\begin{array}{c}\text { Омский голозерный 1, } \\
\text { Нудум (nudum) }\end{array}$ \\
\hline Масса 1000 зерен, г & $46-55$ & $34-45$ & $41-50$ \\
\hline $\begin{array}{l}\text { Вегетационный период, } \\
\text { дней }\end{array}$ & $68-82$ & $85-88$ & $74-90$ \\
\hline $\begin{array}{l}\text { Средняя урожайность, } \\
\text { ц/га }\end{array}$ & 21,8 & 47,4 & 21,2 \\
\hline Устойчивость & $\begin{array}{c}\text { К полеганию и } \\
\text { засухе на уровне } \\
\text { или выше стан- } \\
\text { дарта }\end{array}$ & $\begin{array}{c}\text { К полеганию, } \\
\text { осыпанию, } \\
\text { засухе на уровне } \\
\text { стандарта }\end{array}$ & $\begin{array}{c}\text { К полеганию выше сред- } \\
\text { ней. Засухоустойчивость } \\
\text { уступает стандартам }\end{array}$ \\
\hline
\end{tabular}

Таблица 2

Суммарное содержание антиоксидантов в исходном зерне и талгане, изготовленном из разных сортов ячменя по традиционной и инновационной технологиям

\begin{tabular}{|c|c|c|c|}
\hline \multirow{2}{*}{ Элюент } & \multicolumn{3}{|c|}{ Сорт } \\
\hline & Биом & Красноярский 91 & Омский голозерный 1 \\
\hline \multicolumn{4}{|c|}{ ССА (мг/100 г), исходное зерно } \\
\hline Вода, бидистиллят & $51,0 \pm 0,5 \mathrm{a}$ & $77,3 \pm 0,66$ & $57,7 \pm 0,5$ в \\
\hline 70\%-й спирт & $48,3 \pm 0,4 a$ & $75,8 \pm 0,66$ & $53,4 \pm 0,8$ в \\
\hline \multicolumn{4}{|c|}{ ССА (мг/100 г), зерно после традиционной обработки (талган) } \\
\hline Вода, бидистиллят & $49,1 \pm 0,2 a^{*}$ & $49,2 \pm 0,9 a^{*}$ & $54,3 \pm 0,26^{*}$ \\
\hline 70\%-й спирт & $48,2 \pm 0,1 \mathrm{a}$ & $45,2 \pm 0,2 \sigma^{*}$ & $49,2 \pm 0,2 \mathrm{~B}^{*}$ \\
\hline \multicolumn{4}{|c|}{ ССА (мг/100 г), зерно после инновационной обработки (талган) } \\
\hline Вода, бидистиллят & $60,1 \pm 0,2 a^{*}$ & $69,6 \pm 0,4 \sigma^{*}$ & $66,4 \pm 0,6 \mathrm{~B}^{*}$ \\
\hline 70\%-й спирт & $58,1 \pm 0,5 a^{*}$ & $65,1 \pm 0,4 \sigma^{*}$ & $56,4 \pm 0,4 a^{*}$ \\
\hline
\end{tabular}

Примечание. Средняя арифметическая величина и ошибка средней; значения в колонках с разными буквами различаются существенно между собой в пределах каждой строки по t-критерию при p $\leq 0,05$; * ${ }^{3 н а ч е н и я ~ м е ж д у ~ и с х о д н ы м ~ з е р н о м ~ и ~ в а р и а н т а м и ~ е г о ~ о б р а б о т к и ~ р а з л и ч а ю т с я ~ с у щ е с т в е н н о ~}$ между собой в пределах каждого элюента и каждого сорта по t-критерию при p $\leq 0,05$.

Практически у всех образцов талгана регистрировались значимые изменения в уровнях ССА по сравнению с исходным зерном. Этот результат не зависел от используемого элюента и способа приготовления продукта. При этом у всех образцов талгана, изготовленных по традиционному способу, наблюдалось снижение уровня ССА по сравнению с исходным зерном, а у полученных по инновационному способу, напротив, регистрировалось его увеличение (кроме талгана, приготовленного из сорта Красноярский 91). Правда, в последнем случае величина такого уменьшения была в три раза менее выраженной. При изготовлении талгана по инновационной технологии, когда ячменное зерно сначала измельчали, а затем проводили его термическую обработку, уровень ССА в продукте имел более высокие значения в сравнении с традиционной методикой. Исходя из установленного факта, можно предположить, что дли- 
тельное воздействие высокой температуры при обработке зерна является фактором, снижающим содержание антиоксидантов в продукте.

C помощью использования трехфакторного анализа было установлено (рис.), что на уровень ССА в талгане существенное влияние оказывает способ его изготовления, на долю данного фактора приходится 81,7 \%. На порядок ниже оказывает влияние на величину ССА природа растворителя. Доля генотипа и остальных факторов составляет около 2 и $4 \%$ соответственно. В порядке уменьшения влияния все факторы можно расположить следующим образом: «способхгенотип» > «элюентхгенотип» > «элюентхспособ» > «элюентхгенотипхспособ».
Выводы. На территории Республики Хакасия местное население традиционно использует в пищу продукты, изготовленные на основе зерна пшеницы и ячменя, особенно среди них популярен талган. Представленные в работе данные свидетельствуют, что изменение последовательности этапов изготовления талгана приводит не только к сокращению времени термической обработки, но и к повышению уровня ССА в готовом продукте. По данному критерию он отвечает требованиям, предъявляемым к функциональным продуктам питания, и может быть введен в диету здорового питания населения.

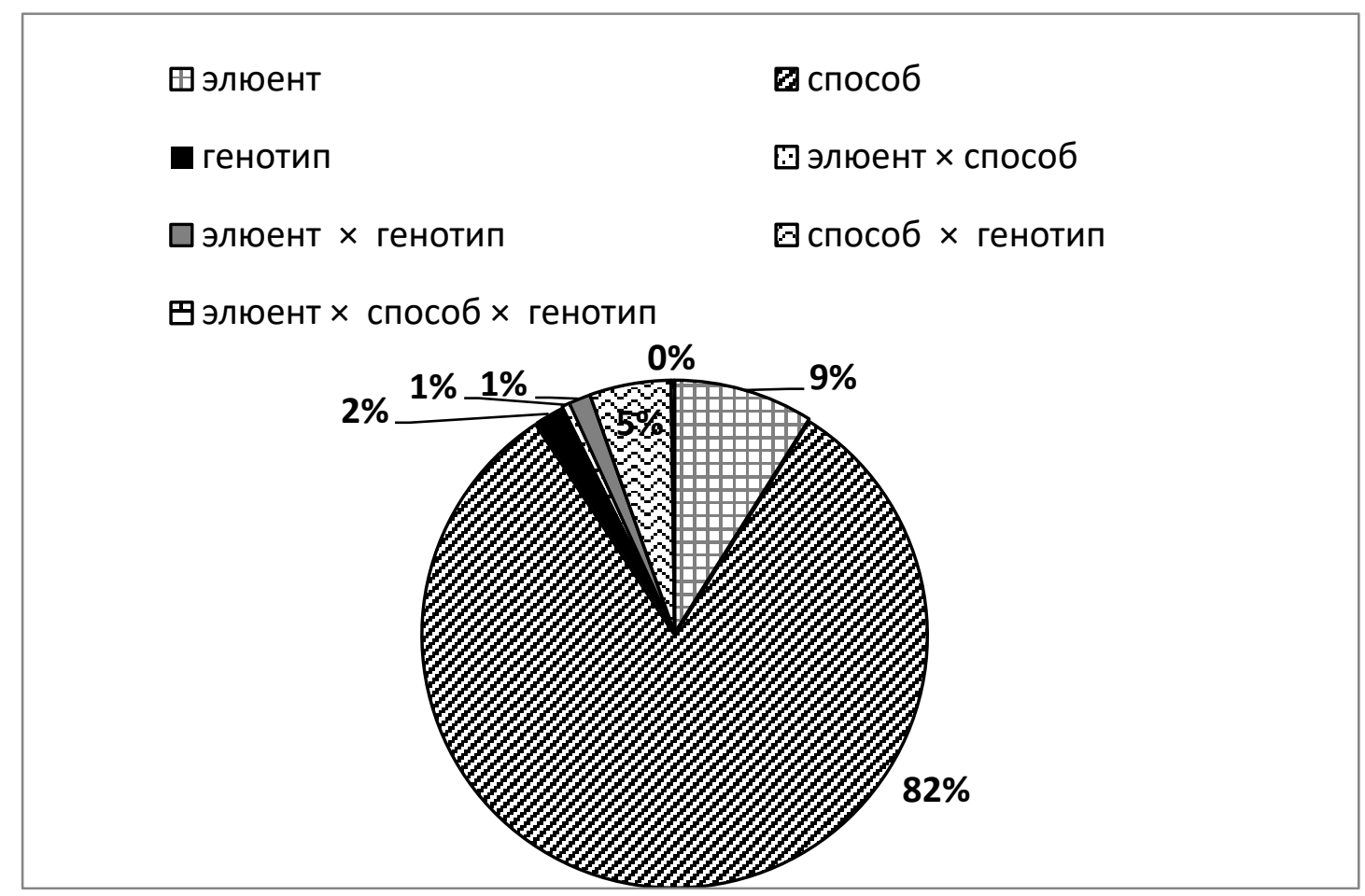

Влияние условий изготовления ячменного талгана на суммарное содержание в нем антиоксидантов

\section{Литература}

1. Улумбекова Г.Э. Здоровье населения в Российской Федерации: фракторы риска и роль здорового питания // Вопросы питания. - 2010. -Т. 79, № 2. - С. 33-38.

2. Блохина Л.В., Кондакова Н.М., Погожева A.B. [и др.]. Изучение фактического питания - важное звено в многоуровневой системе диагностики нарушений пищевого статуса у пациентов с ожирением // Вопросы питания. - 2009. - Т. 78, № 5. - С. 35-39.

3. Gupta C., Prakash D. Nutraceuticals for geriatrics // Journal of Traditional and Complementary Medicine. - 2015. - V. 5. - P. 5-14.

4. Блажей А., Шутьй Л. Фенольные соединения растительного происхождения. - М.: Мир, 2015. - 240 c.

5. Яшин А., Яшин Я., Федина П. [и др.]. Определение природных антиоксидантов в пи- 
щевых злаках и бобовых культурах // Аналитика. - 2012. - Т. 2, № 1. - С. 32-36.

6. Полонский В.И., Сумина А.В., Шалдаева T.M. Суммарное содержание природных антиоксидантов в зерне ячменя в различных условиях выращивания // Вестник КрасГАУ. - 2017. - № 12. - С. 21-28.

7. Бородулин Д.М., Шулбаева М.Т., Мусина О.Н. [и др.]. Инновационная технология получения талгана как компонента функциональных пищевых продуктов, учитывающих национальные традиции питания // Техника и технология пищевых производств. - 2017. - T. 46, № 3. - C. 15-22.

8. Акимова О.И., Акимов Д.Н. Использование статистических методов обработки опытных данных при выполнении студенческих научных работ // Вестник ХГУ. - 2016. № 18. - C. 76-78.

\section{Literatura}

1. Ulumbekova G.Je. Zdorov'e naselenija v Rossijskoj Federacii: faktory riska i rol' zdorovogo pitanija // Voprosy pitanija. - 2010. -T. 79, № 2. - S. 33-38.

2. Blohina L.V., Kondakova N.M., Pogozheva A.V. [i dr.]. Izuchenie fakticheskogo pitanija vazhnoe zveno $v$ mnogourovnevoj sisteme diagnostiki narushenij pishhevogo statusa $u$ pacientov s ozhireniem // Voprosy pitanija. 2009. - T. 78, № 5. - S. 35-39.

3. Gupta C., Prakash D. Nutraceuticals for geriatrics // Journal of Traditional and Complementary Medicine. - 2015. - V. 5. - P. 5-14.

4. Blazhej A., Shutyj L. Fenol'nye soedinenija rastitel'nogo proishozhdenija. - M.: Mir, 2015. $-240 \mathrm{~s}$.

5. Jashin A., Jashin Ja., Fedina P. [i dr.]. Opredelenie prirodnyh antioksidantov $v$ pishhevyh zlakah i bobovyh kul'turah // Analitika. - 2012. - T. 2, № 1. - S. 32-36.

6. Polonskij V.I., Sumina A.V., Shaldaeva T.M. Summarnoe soderzhanie prirodnyh antioksidantov $v$ zerne jachmenja $v$ razlichnyh uslovijah vyrashhivanija // Vestnik KrasGAU. 2017. - № 12. - S. 21-28.

7. Borodulin D.M., Shulbaeva M.T., Musina O.N. [i dr.]. Innovacionnaja tehnologija poluchenija talgana kak komponenta funkcional'nyh pishnevyh produktov, uchityvajushhih nacional'nye tradicii pitanija // Tehnika i tehnologija pishhevyh proizvodstv. - 2017. T. 46, № 3. - $\quad$ S. 15-22.

8. Akimova O.I., Akimov D.N. Ispol'zovanie statisticheskih metodov obrabotki opytnyh dannyh pri vypolnenii studencheskih nauchnyh rabot // Vestnik HGU. - 2016. - № 18. S. 76-78. 